\section{Genzyme Transgenics buys TSI for \$30 million}

NEW YORK-The biopharmaceutical industry's long predicted-and long feared-wave of consolidation may finally be accelerating, as Genzyme Transgenics' (GT, Framingham, MA) recent acquisition of TSI (Milford, MA) attests. GT purchased TSI through a stock swap valued at roughly $\$ 30$ million, with TSI shareholders exchanging five shares of TSI stock for one share of GT stock. Completion of the merger, though, is pending the outcome of a suit filed against TSI by its shareholders, one claiming that GT is paying far too little for TSI.

By acquiring TSI, GT creates a company that can potentially take a therapeutic protein or diagnostic protein from A to Z. The combined company plans to use GT's expertise in pharming to develop protein-producing transgenic animals and TSI's expertise in preclinical testing and clinical testing to push those transgenic-animal-produced proteins to the market. "The missions of the two companies are similar: to reduce the time and cost of bringing biopharmaceuticals and pharmaceuticals to market," says James Geraghty, GT's president and chief executive officer.

$\mathrm{GT}$ - which engineers mice, rabbits, and goats to produce recombinant proteins in their milkmakes these proteins far more efficiently than traditional cell-culture production and purification methods. Indeed, for a given protein, GT estimates that it beats the cost of cell-culture production by about 50 percent. For instance, GT has created goats that produce in their milk $7 \mathrm{~g} / \mathrm{l}$ of antithrombin-III (ATIII), an anticoagulant. By comparison, AT-III is typically produced in cell culture at concentrations below $50 \mathrm{mg} / \mathrm{l}$.

For its part, TSI became an acquisition candidate because of a flurry of its own acquisitions throughout 1991 and 1992. In all, TSI purchased seven companies, giving it three toxicology and preclinical-efficacy testing facilities, two human clinical-testing sites, one manufacturing-support laboratory, and one manufacturing and sales facility for diagnostic products. TSI's acquisition strategy proved a bust, however, as it soon began closing unprofitable facilities, eventually decreasing corporate overhead by two-thirds. In fact, though TSI's revenues increased steadily from 1991 to 1993 , so did its net losses. In 1991, TSI posted revenues of $\$ 23.3$ million, with a net loss of $\$ 376,000$. In 1992, TSI's revenues increased to $\$ 35.4$ million, though its net loss soared to $\$ 11.2$ million. And in 1993, TSI's revenues jumped to $\$ 58.3$ million, though its net loss ballooned to $\$ 32$ million.

GT, on the other hand, had far more modest revenues of $\$ 3.2$ million in 1993, with a net loss of $\$ 1.2$ million. Currently, AT-III is GT's lead product, and it expects to enter AT-III in clinical trials by the end of 1995. GT's Geraghty, in fact, believes that the GT/TSI combined staff of 520 employees will speed AT-III's entry into the clinic. -Lesley Wright

Lesley Wright, who lives in New York, is a science writer specializing in biotechnology.

\title{
FDA derails Immunomedics' ImmuRAID-CEA
}

NEW YORK-Immunomedics (Morris Plains, NJ) has received a letter from the Food and Drug Administration(FDA, Rockville, MD) indicating that its product license application for ImmuRAID-CEA for colorectal cancer imaging - an application that the firm filed with the FDA in April 1991-is not approvable at this time. Immunomedics is currently meeting with the FDA to clarify issues raised in the agency's letter about ImmuRAID-CEA, and the firm is uncertain how long the regulatory delay will last or whether the product will have to undergo further clinical testing. Immunomedics also filed for marketing approval of ImmuRAID-CEA in Canada in February 1992 and in Europe in March 1992, neither of which has yet to grant such approval.

ImmuRAID-CEA-a monoclonal antibody (MAb) fragment labeled with the radioisotope, tech- netium-99m - attaches to the tumor marker, carcinoembryonic antigen (CEA). CEA appears in abundance on virtually all cancers of the colon and rectum, and it occurs at elevated levels in three-quarters of all other cancers. Once ImmuRAID-CEA is administered to a patient, the patient is scanned by a gamma camera, a conventional nuclear medicine camera used to display radioisotope concentrations. This allows for the detection of the location and the size of a tumor.

One consequence of the FDA's nonapprovable letter for ImmuRAID-CEA has been the restructuring of a licensing agreement between Immunomedics and the Adria Laboratories (Columbus, $\mathrm{OH})$, a division of Erbamont. The agreement-entered into in July 1991-now provides for Adria to retain exclusive marketing rights to ImmuRAID-CEA in North America, while Immunomedics re- gains North American marketing rights to its ImmuRAID-LL2, a Bcell lymphoma imaging product, and its ImmuRAID-AFP, a liver cancer imaging product. Both products are in phase I/II clinical trials and hold orphan drug status with the FDA. Immunomedics has already received $\$ 8$ million in research and development (R\&D) funding from Adria, and it could receive another $\$ 14.4$ million in R\&D funding by 1996.

Immunomedics has additional imaging products in the pipeline. ImmuRAID-CEA is also in phase III trials for lung cancer and phase I/II trials for breast cancer. ImmuRAID-MN3-which binds to infection-fighting granulocytes-is in phase III trials to detect the location and extent of suspected infections affecting bones and prosthetic joints, as well as foot ulcers in diabetic patients.

-Mike Ginsberg
"The missions

of the two

companies are

similar: to

reduce the time

and cost of

bringing

biopharmaceuticals

and

pharmaceuticals

to market." 